\title{
Use of Lignin-based Carbons for Decolorization of Wastewater Dyes
}

Qin Wu, ${ }^{\mathrm{a}, \mathrm{b}, *}$ Weilong Shao, ${ }^{\mathrm{a}}$ Yujie Zhang, ${ }^{\mathrm{a}}$ Tong $\mathrm{Su},{ }^{\mathrm{a}}$ Xin Zhao, ${ }^{\mathrm{a}, *}$ Fangong Kong, ${ }^{\mathrm{a}}$ Nannan Xia, ${ }^{a}$ and Zhiwei Wang ${ }^{b}$

\begin{abstract}
Hierarchical porous carbons were prepared from several common lignins, including sodium lignosulfonate (SLS), alkali lignin ( $A L$ ), and calcium lignosulfonate (CLS) via one-step carbonization at $800^{\circ} \mathrm{C}$ for $10 \mathrm{~h}$ without oxygen or any additional templating/activation agent for the decolorization of dyes from wastewater. The obtained carbons showed high porosity and microporous-mesoporous-macroporous hierarchical porous structures. The specific surface areas of SLS-C, AL-C, and CLS-C were $346 \mathrm{~m}^{2} / \mathrm{g}$, $405 \mathrm{~m}^{2} / \mathrm{g}$, and $512 \mathrm{~m}^{2} / \mathrm{g}$, respectively. The total pore volumes of SLS-C, $A L-C$, and CLS-C were $0.12 \mathrm{~cm}^{3} / \mathrm{g}, 0.21 \mathrm{~cm}^{3} / \mathrm{g}$, and $0.28 \mathrm{~cm}^{3} / \mathrm{g}$, respectively. The obtained carbon materials displayed excellent adsorption-decolorization abilities for 5 dyes, including ethyl violet, malachite green, cationic brilliant red, acid blue 92, and direct red 23. The concentrations of these 5 dyes in wastewater were reduced by SLS-C from $20 \mathrm{mg} / \mathrm{L}$ to $0.12 \mathrm{mg} / \mathrm{L}, 0.20 \mathrm{mg} / \mathrm{L}, 0.32 \mathrm{mg} / \mathrm{L}, 0.78 \mathrm{mg} / \mathrm{L}$, and $3.77 \mathrm{mg} / \mathrm{L}$, respectively, over a $60 \mathrm{~min}$ treatment. AL-C reduced these concentrations from $20 \mathrm{mg} / \mathrm{L}$ to $0.02 \mathrm{mg} / \mathrm{L}, 0.01 \mathrm{mg} / \mathrm{L}, 0.04 \mathrm{mg} / \mathrm{L}, 0.71 \mathrm{mg} / \mathrm{L}$, and 1.72 $\mathrm{mg} / \mathrm{L}$ over the same time period. In addition, the concentrations of these respective dyes were reduced by CLS-C from $20 \mathrm{mg} / \mathrm{L}$ to $0.01 \mathrm{mg} / \mathrm{L}, 0.01$ $\mathrm{mg} / \mathrm{L}, 0.02 \mathrm{mg} / \mathrm{L}, 0.30 \mathrm{mg} / \mathrm{L}$, and $0.20 \mathrm{mg} / \mathrm{L}$.
\end{abstract}

Keywords: Calcium lignosulfonate; Alkali lignin; Sodium lignosulfonate; Carbonization; Decolorization

Contact information: a: State Key Laboratory of Biobased Material and Green Papermaking, Qilu

University of Technology, Shandong Academy of Sciences, Jinan 250353 CHN; b: Guangxi Key

Laboratory of Clean Pulp \& Papermaking and Pollution Control, Nanning 530004 CHN;

* Corresponding author: wuqin19820107@163.com

\section{INTRODUCTION}

Approximately 80,000 tons of dye are produced annually worldwide for use in the textile, printing and dyeing, papermaking, leather making, and paint industries (Lee et al. 2006; Zhang et al. 2016). Discharged dye wastewater from mass production and the application of dyestuffs causes serious environmental pollution (Wu et al. 2016) and has unfavorable effects on human life, plants, and animals. This is due to the dyes' difficult biochemical degradation, oxidation resistance, strong thermal stability, and highly toxic and carcinogenic properties (Liu and Sun 2007). Activated carbons are effective adsorbents for the removal of dyes from aqueous solutions due to their extremely high specific surface areas and favorable pore structures (Katheresan et al. 2018). The cost of activated carbons derived from wood, coal, and other carbonaceous materials is relatively high due to their difficult regeneration. Therefore, recent research has focused on finding a precursor to activated carbon that is low-cost yet abundant.

Industrial lignin is a by-product of the pulp and paper industry. Every year, approximately 70 million tons of lignin is produced globally, and about $98 \%$ of this is 
burned directly as low-grade fuel (Lora and Glasser 2002), which not only is a waste of resources but also causes secondary environmental pollution. Lignin has received considerable attention for carbon production because of its high carbon content, highly aromatic cyclization structure, high molecular weight, excellent biodegradability, and low price (Fu et al. 2013; Chatterjee and Saito 2015). Much research has focused on the application of carbons derived from lignin for the preparation of supercapacitors (SalinasTorres et al. 2016; Pang et al. 2017, 2018). However, less is known about its use in the decolorization of dye wastewater. Carbon composite lignin-based adsorbents have been prepared through hydrothermal methods using glucose as a carbon source and calcium lignosulfonate and triethylene tetramine as raw materials. This adsorbent was used for the adsorption of Congo red and eriochrome blue black $\mathrm{R}$, and when the dye concentration was $40 \mathrm{mg} / \mathrm{L}^{-1}$, the Congo red and eriochrome blue black $\mathrm{R}$ dye removal rates reached $99 \%$ (Wang et al. 2018).

Recently, the production of many carbon materials has required the introduction of a hard/soft template or an activation agent during the preparation process to achieve high specific surface area and high adsorption (Zhao et al. 2015; Bulavová et al. 2018). In this work, hierarchical porous carbons were prepared from several common lignins, including calcium lignosulfonate (CLS), alkali lignin (AL), and sodium lignosulfonate (SLS), via one-step carbonization without oxygen or any additional templating/activation agent. The obtained calcium lignosulfonate-based carbon (CLS-C), alkali lignin-based carbon (ALC), and sodium lignosulfonate-based carbon (SLS-C) were used to treat five kinds of dyes commonly found in industrial wastewater, including Ethyl Violet (EV), Malachite Green (MG), Cationic Brilliant Red (CBR), Acid Blue 92 (AB 92), and Direct Red 23 (DR 23). The feasibility of industrial lignin-based carbons for the decolorization of dye in wastewater is explored in this paper. In comparison with other methods, the advantages of the protocol used to prepare lignin-based carbons may include the controlled porous structures well by self-assembly during one-step carbonization process; such potential advantages are inherent in the lignin-based carbons themselves, which contain the metals $\mathrm{Na}$ and $\mathrm{Ca}$ (Ma et al. 2014; Chen et al. 2019).

\section{EXPERIMENTAL}

\section{Materials Synthesis}

The used lignin specimens labeled as industrial grade were purchased from the chemical reagent factory (Tianjin FuChen). The lignin-based carbons were prepared via one-step carbonization. In brief, $2 \mathrm{~g}$ samples of CLS, AL, and SLS were heated to $800^{\circ} \mathrm{C}$ for $2 \mathrm{~h}$ at a heating rate of $5^{\circ} \mathrm{C} / \mathrm{min}^{-1}$ under nitrogen gas in a vacuum tube high temperaturesintering furnace (OTF-1200X, KJ Group, Richmond, CA, USA). Finally, the products were prepared by filtration, rinsed with water, and dried at $105{ }^{\circ} \mathrm{C}$ overnight. The resultant carbon materials were named CLS-C, AL-C, and SLS-C.

\section{Characterization}

X-ray diffraction (XRD) patterns were recorded on an X-ray diffractometer (D8ADVANCE, Bruker AXS, Karlsruhe, Germany) with $\mathrm{Cu} \mathrm{K \alpha}$ radiation. The surface area and pore size distribution (PSD) of CLS-C, AL-C, and SLS-C were analyzed by the Brunauer-Emmett-Teller (BET) method and non-local density functional theory (NLDFT) 
model, respectively. The t-plot method was adopted to analyze the microporous characteristics, and the total pore volume was calculated from the nitrogen uptake at a relative pressure of $c a$. 0.995 .

\section{Dye Absorption}

To evaluate the potential of the prepared CLS-C, AL-C, and SLS-C for dye wastewater treatment, 5 kinds of dyes, including EV, MG, CBR, AB 92, and DR 23, which can be viewed as model dyes for dye adsorption from wastewater, were used. For batch adsorption studies, a series of $50 \mathrm{~mL}$ dye solutions, with an initial concentration of $20 \mathrm{mg} / \mathrm{L}$ were placed in a $150 \mathrm{~mL}$ sealed conical flask and subsequently different lignin-based carbons were added at a dosage of $6 \mathrm{~g} / \mathrm{L}$. The conical flasks were then shaken in a thermostated water bath shaker at $200 \mathrm{rpm}$ at a constant temperature of $25{ }^{\circ} \mathrm{C}$ for a defined time ranging from 0 to $60 \mathrm{~min}$. After shaking, a centrifuge (TGL-20M) was used to separate the adsorbent from the solution at a rate of $1000 \mathrm{rpm}$ for $10 \mathrm{~min}$. The concentration of the remaining dye solution was calculated by the absorbance value, which was measured using a spectrophotometer (UV-2600) at its maximum wavelength.

To determine the maximum absorption wavelength of different dyes, absorbance curves for EV, MG, CBR, AB 92, and DR 23 at different standard concentrations were obtained. The standard solutions curve was plotted by measuring the absorbance of standard solutions with different concentrations at the maximum absorption wavelength, which could yield a standard linear equation relating concentration to absorbance.

In order to ensure the data reliability, 5 replicas of each dye decolorization assays were conducted.

\section{RESULTS AND DISCUSSION}

Black firm porous carbons were prepared from brown powdered CLS, AL, and SLS via one-step carbonization at $800{ }^{\circ} \mathrm{C}$ for $10 \mathrm{~h}$ under nitrogen gas. The obtained carbon materials displayed excellent adsorption-decolorization abilities for 5 kinds of dyes in wastewater, including EV, MG, CBR, AB 92, and DR 23.

\section{Characteristics of CLS-C, AL-C, and SLS-C}

XRD (Fig. 1) showed that the prepared carbon samples from lignin had similar XRD patterns.

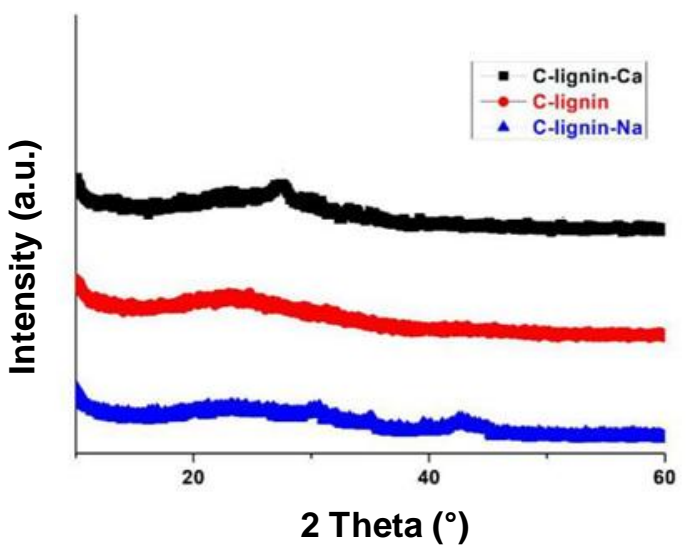

Fig. 1. $\mathrm{XRD}$ of different carbon samples from lignin 
Diffraction peaks appeared at $2 \theta \approx 23^{\circ}$ or $42^{\circ}$, with large widths and low intensities, characteristic of graphitic carbon (Gao et al. 2014). This graphitic structure resulted in the adsorption properties for different dyes, discussed in more depth below.

The nitrogen adsorption isotherms and the corresponding pore size distribution curves of the different lignin carbon samples are shown in Fig. 2. The adsorption capacities of all samples below a relative pressure $\left(P / P_{0}\right)$ of 0.1 symbolize typical microporous characteristics. Meanwhile, the hysteresis loop at a relative pressure $\left(P / P_{0}\right)$ of 0.4 to 0.95 is associated with capillary condensation occurring in the mesopores (Riachy et al. 2017). All of the as-prepared carbon materials showed a type-IV adsorption isotherm, indicating typical micropores and mesopores structures. However, a higher adsorption capacity below a relative pressure $\left(P / P_{0}\right)$ of 0.1 for CLS-C was caused by the increasing of number of micropores (Tian et al. 2017).
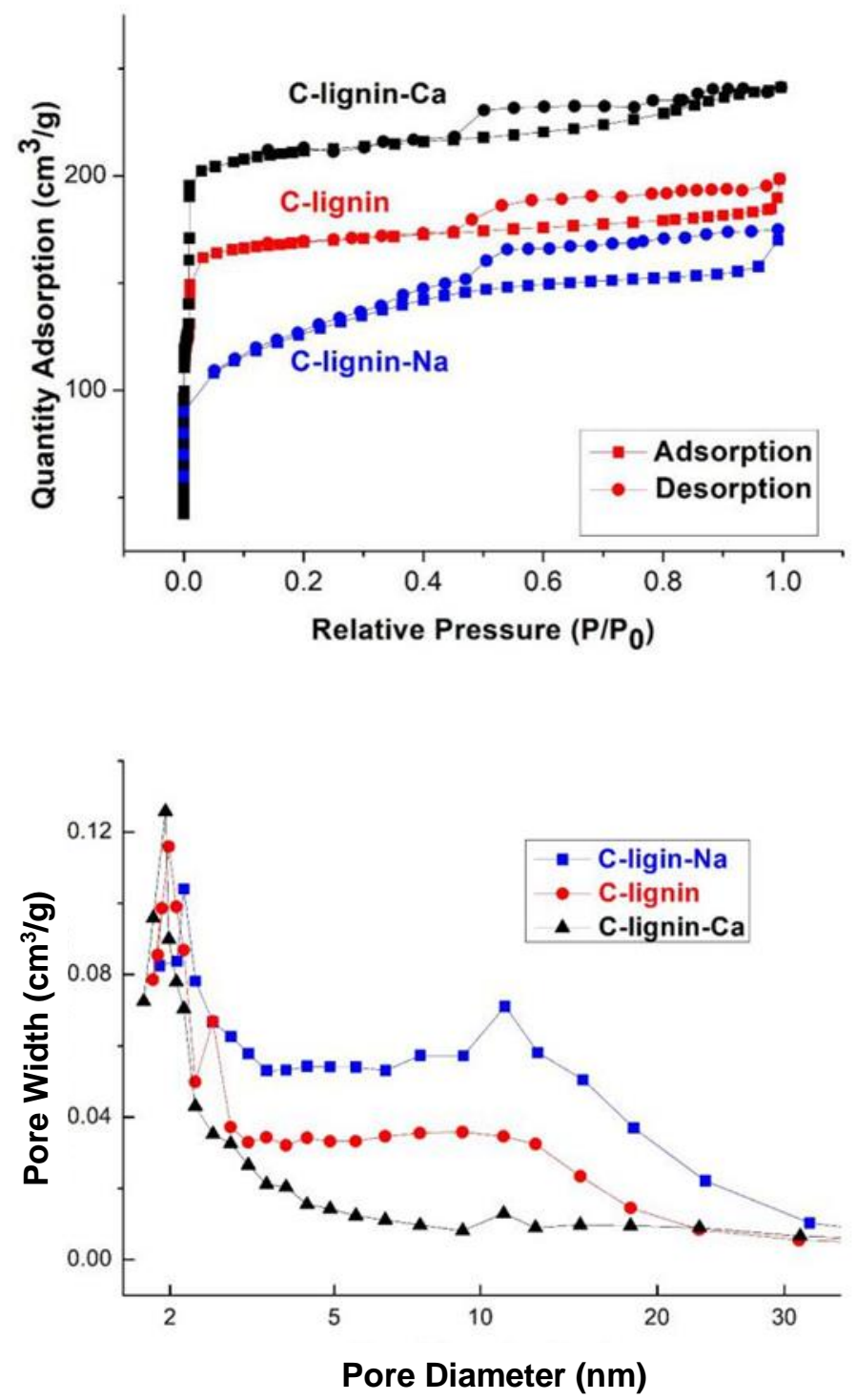

Fig. 2. (a) Nitrogen sorption isotherms and (b) pore size distribution of the prepared carbon samples 
A larger hysteresis loop at a relative pressure $\left(P / P_{0}\right)$ of 0.4 to 0.95 for SLS-C resulted from the higher mesoporous content as well. Compared with AL-C, the enhanced microporous adsorption content for CLS-C was attributed to $\mathrm{Ca}$ being present in the structure during the carbonization process, and further porous structures occurred after the dissolution of CLS. Moreover, the mesoporous content increased in SLS-C due to Na eutectic salt dissolution. These results suggested that $\mathrm{Ca}$ eutectic salts were more favorable to the formation of micropores, and $\mathrm{Na}$ eutectic salts were more favorable to the formation of mesopores (Ma et al. 2014; Chen et al. 2019).

The pore size distribution plots of the prepared samples are shown in Fig. 2b. The prepared carbon materials exhibited a uniform pore size distribution, and their pore size was mainly distributed around $2.0 \mathrm{~nm}$, with a sharp peak at $2 \mathrm{~nm}$. The higher peak occurring for CLS-C at $2.0 \mathrm{~nm}$ showed the presence of more micropores. As can be seen from Fig. 3b, SLS-C had a pore size distribution from $5.0 \mathrm{~nm}$ to $20 \mathrm{~nm}$ and a peak at 12 $\mathrm{nm}$, which indicated that larger mesopores were generated in the SLS-C sample as compared to the CLS-C sample. These results showed that the types of eutectic salts present during carbonization were important influencing factors on the textural properties of the resulting carbon materials (Zhao et al. 2017). This outcome corresponded to the nitrogen adsorption isotherms results. Thus, it appeared that $\mathrm{Na}$ salts play a role as templates for mesopores, while $\mathrm{Ca}$ salts work as activation agents for micropores.

The textural parameters of different carbon samples are listed in Table 1. The surface area, pore volume, and $S_{\text {micro }} / S_{\text {BET }}$ of AL-C were $405 \mathrm{~m}^{2} / \mathrm{g}, 0.21 \mathrm{~cm}^{3} / \mathrm{g}$, and $73 \%$, respectively. However, SLS-C showed lower specific surface area $\left(346 \mathrm{~m}^{2} / \mathrm{g}\right)$ and pore volume $\left(0.12 \mathrm{~cm}^{3} / \mathrm{g}\right)$ as well as a $S_{\text {micro }} / S_{\text {BET }}$ of only $50 \%$. CLS-C showed higher specific surface area $\left(512 \mathrm{~m}^{2} / \mathrm{g}\right)$ and pore volume $\left(0.28 \mathrm{~cm}^{3} / \mathrm{g}\right)$, with a $S_{\text {micro }} / S_{\text {BET }}$ of $89 \%$. Furthermore, the average pore size moved from mesopores in SLS-C (4.5 nm) and AL-C $(3.2 \mathrm{~nm})$ to micropores in CLS-C $(1.9 \mathrm{~nm})$.

These results suggest that both $\mathrm{Ca}$ and $\mathrm{Na}$ salts have important roles in controlling the surface area and porous percentage of resulting carbons. Na salt plays a crucial role in the formation of mesopores, and conversely, the effect of $\mathrm{Ca}$ salt is to promote the generation of micropores, resulting in a larger surface area in the resulting material. In particular, the high surface area of the material exposes more active centers to reactants, and an appropriate pore volume should improve the adsorption and diffusion of reactant molecules (Liu and Antonietti 2014).

Table 1. Textural Parameters of Different Carbon Samples

\begin{tabular}{|c|c|c|c|c|}
\hline Sample & $\begin{array}{c}S_{\text {BET }} \\
\left(\mathrm{m}^{2} / \mathrm{g}\right)\end{array}$ & $\begin{array}{c}S_{\text {micro/ }} / S_{\text {BET }} \\
(\%)\end{array}$ & $\begin{array}{c}V_{\text {total }} \\
\left(\mathrm{cm}^{3} / \mathrm{g}\right)\end{array}$ & $\begin{array}{c}\text { Average pore size } \\
(\mathrm{nm})\end{array}$ \\
\hline CLS-C & 512 & 89 & 0.28 & 1.9 \\
\hline AL-C & 405 & 73 & 0.21 & 3.2 \\
\hline SLS-C & 346 & 50 & 0.12 & 4.5 \\
\hline
\end{tabular}

\section{Plotting of Standard Concentration Curve of Solution}

The absorbance curves for EV, MG, CBR, AB 92, and DR 23 at different standard concentrations were obtained to determine the maximum absorption wavelength of different dyes. The results showed that the over wavelengths ranging from $200 \mathrm{~nm}$ to 800 $\mathrm{nm}$, the maximum absorption wavelengths of EV, MG, CBR, AB 92, and DR 23 were 596 $\mathrm{nm}, 618 \mathrm{~nm}, 514 \mathrm{~nm}, 622.5 \mathrm{~nm}$, and $508 \mathrm{~nm}$, respectively. The standard solutions curve in 
each case was plotted by measuring the absorbance of standard solutions with different concentrations at the maximum absorption wavelength. The standard linear equations relating concentration $(\mathrm{X})$ to absorbance $(\mathrm{Y})$ were obtained as follows. For $\mathrm{EV}, \mathrm{Y}=0.2489 \mathrm{X}$ $\left(\mathrm{R}^{2}=0.9969\right)$. For $\mathrm{MG}, \mathrm{Y}=0.0856 \mathrm{X}\left(\mathrm{R}^{2}=0.9966\right)$. For $\mathrm{CBR}, \mathrm{Y}=0.0946 \mathrm{X}\left(\mathrm{R}^{2}=0.9982\right)$. For $\mathrm{AB} 92, \mathrm{Y}=0.083 \mathrm{X}\left(\mathrm{R}^{2}=0.9961\right)$. For DR 23, $\mathrm{Y}=0.0692 \mathrm{X}\left(\mathrm{R}^{2}=0.9987\right)$. The above standard linear equations were used to calculate the corresponding concentrations of dyes (Wang et al. 2006; Daneshvar et al. 2007; Fathi et al. 2015; Mohajershojaei et al. 2015).

\section{Dye Adsorption by CLS-C}

The five kinds of simulated dye wastewaters, which contained EV, MG, CBR, AB 92, and DR 23, were treated with CLS and CLS-C. The results are shown in Fig. 3. Those treated with CLS-C could adsorb EV, MG, CBR, AB 92, and DR 23 significantly in a short time. In contrast, CLS performed poorly for adsorption. CLS-C reduced the concentration of EV, MG, CBR, AB 92, and DR 23 from $20 \mathrm{mg} / \mathrm{L}$ to $0.15 \mathrm{mg} / \mathrm{L}, 0.03 \mathrm{mg} / \mathrm{L}, 0.06 \mathrm{mg} / \mathrm{L}$, $1.08 \mathrm{mg} / \mathrm{L}$, and $2.80 \mathrm{mg} / \mathrm{L}$ in $10 \mathrm{~min}$, respectively. Furthermore, the above concentrations continued to decrease to $0.01 \mathrm{mg} / \mathrm{L}, 0.01 \mathrm{mg} / \mathrm{L}, 0.02 \mathrm{mg} / \mathrm{L}, 0.30 \mathrm{mg} / \mathrm{L}$, and $0.20 \mathrm{mg} / \mathrm{L}$ after $60 \mathrm{~min}$. CLS, however, could only reduce the concentration of EV, MG, CBR, AB 92, and DR 23 from $20 \mathrm{mg} / \mathrm{L}$ to $14.82 \mathrm{mg} / \mathrm{L}, 9.28 \mathrm{mg} / \mathrm{L}, 12.37 \mathrm{mg} / \mathrm{L}, 8.31 \mathrm{mg} / \mathrm{L}$, and $16.05 \mathrm{mg} / \mathrm{L}$ after $10 \mathrm{~min}$, respectively. After $60 \mathrm{~min}$ of incubation, the above concentrations only decreased to $12.96 \mathrm{mg} / \mathrm{L}, 8.22 \mathrm{mg} / \mathrm{L}, 9.63 \mathrm{mg} / \mathrm{L}, 7.47 \mathrm{mg} / \mathrm{L}$, and $12.51 \mathrm{mg} / \mathrm{L}$. To summarize, both the type of dye and the adsorption time can affect the decolorization effect of CLS-C, and CLS-C had better decolorization efficiency for dye wastewater than CLS.
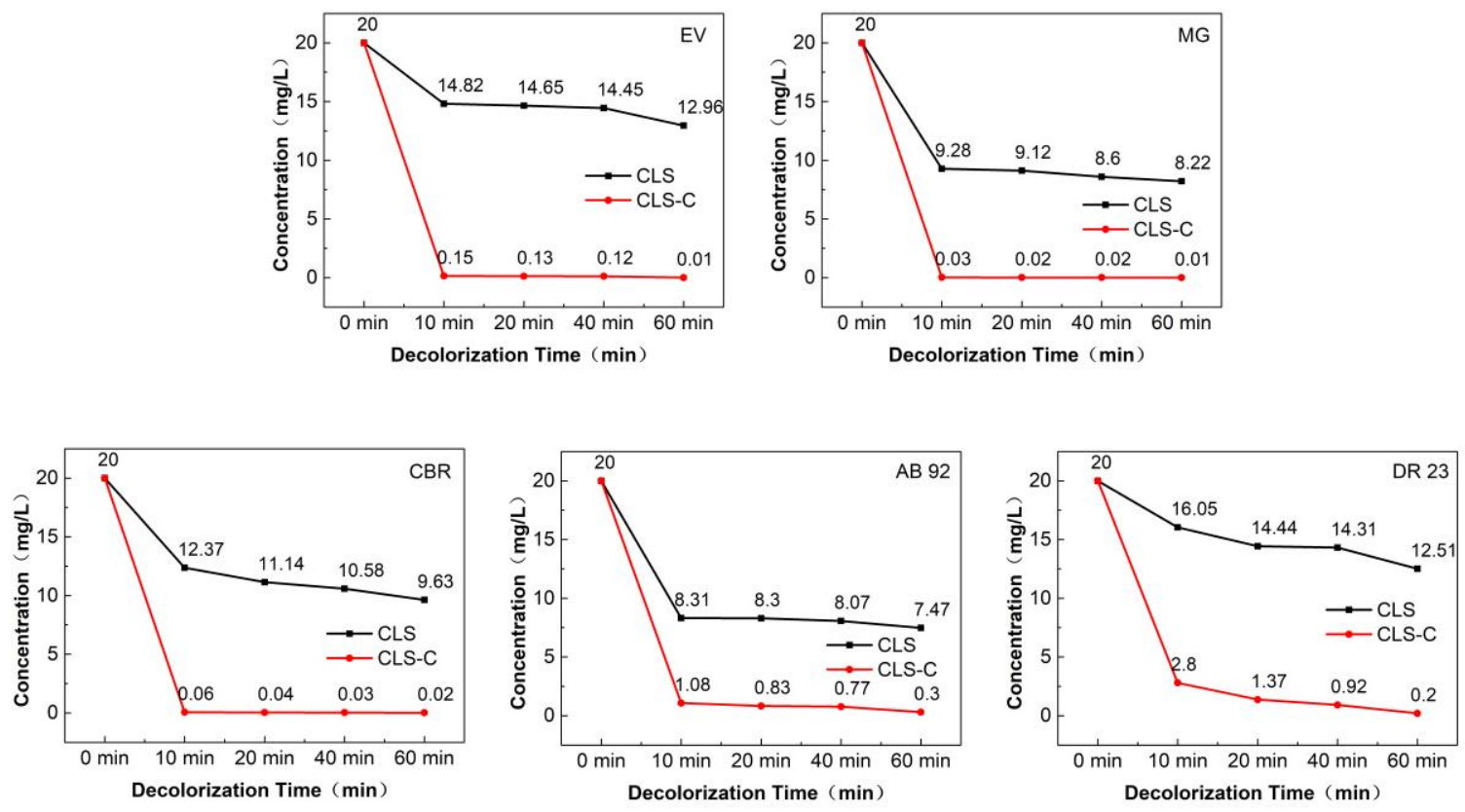

(Note: The data are average values of 5 replicates. $R S D=0.5-2.5 \%, R S D$ is relative standard deviation)

Fig. 3. Decoloration of dye wastewater by CLS and CLS-C 


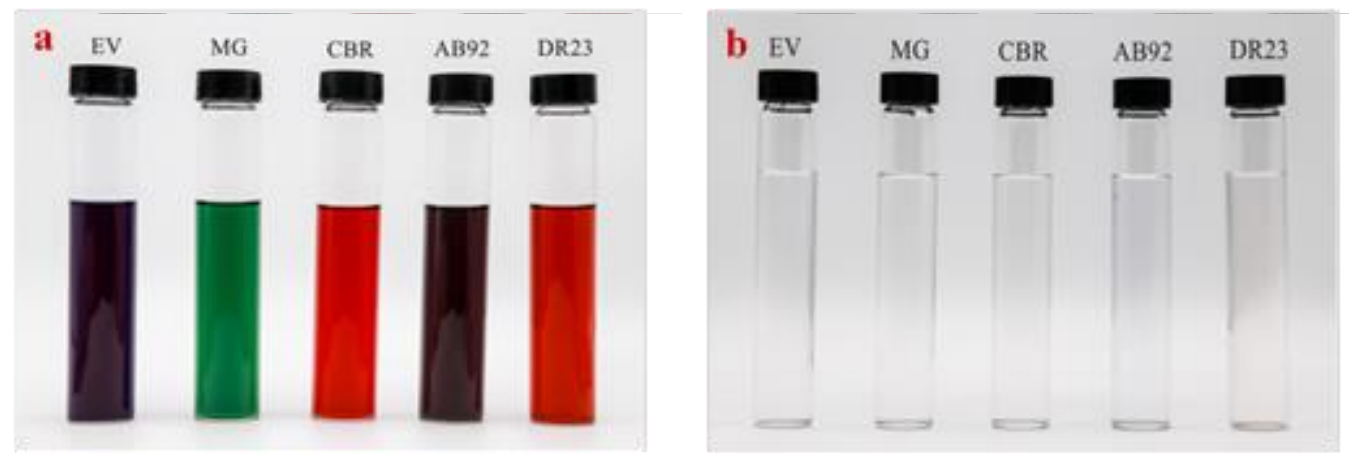

Fig. 4. Decolorization of dyes by CLS and CLS-C

\section{Dye Adsorption by AL-C}

The five kinds of simulated dye wastewater containing EV, MG, CBR, AB 92, and DR 23 were treated by AL and AL-C, and the results are shown in Fig. 5. AL-C could adsorb EV, MG, CBR, AB 92, and DR 23 significantly in 20 min. However, AL adsorbed dyes poorly and even increased the chrominance of wastewater because of its water solubility. AL-C made the concentration of EV, MG, CBR, AB 92, and DR 23 decrease from $20 \mathrm{mg} / \mathrm{L}$ to $0.15 \mathrm{mg} / \mathrm{L}, 0.22 \mathrm{mg} / \mathrm{L}, 0.36 \mathrm{mg} / \mathrm{L}, 1.25 \mathrm{mg} / \mathrm{L}$, and $5.45 \mathrm{mg} / \mathrm{L}$, respectively, in $20 \mathrm{~min}$. The above concentrations continued to decrease to $0.02 \mathrm{mg} / \mathrm{L}, 0.01$ $\mathrm{mg} / \mathrm{L}, 0.04 \mathrm{mg} / \mathrm{L}, 0.71 \mathrm{mg} / \mathrm{L}$, and $1.72 \mathrm{mg} / \mathrm{L}$ after $60 \mathrm{~min}$. When AL was added to the 5 different dyes containing wastewater, the concentration of EV, MG, CBR, AB 92, and DR 23 was $13.36 \mathrm{mg} / \mathrm{L}, 8.77 \mathrm{mg} / \mathrm{L}, 19.39 \mathrm{mg} / \mathrm{L}, 10.82 \mathrm{mg} / \mathrm{L}$, and $34.08 \mathrm{mg} / \mathrm{L}$, respectively, within $20 \mathrm{~min}$. Additionally, the above values transformed to $11.37 \mathrm{mg} / \mathrm{L}, 7.61 \mathrm{mg} / \mathrm{L}, 18.39$ $\mathrm{mg} / \mathrm{L}, 10.45 \mathrm{mg} / \mathrm{L}$, and $32.34 \mathrm{mg} / \mathrm{L}$ after treatment for $60 \mathrm{~min}$. To summarize, AL-C had better decolorization effects on dye wastewater than AL, and the type of dye and the adsorption time impacted the decolorization effect of AL-C.
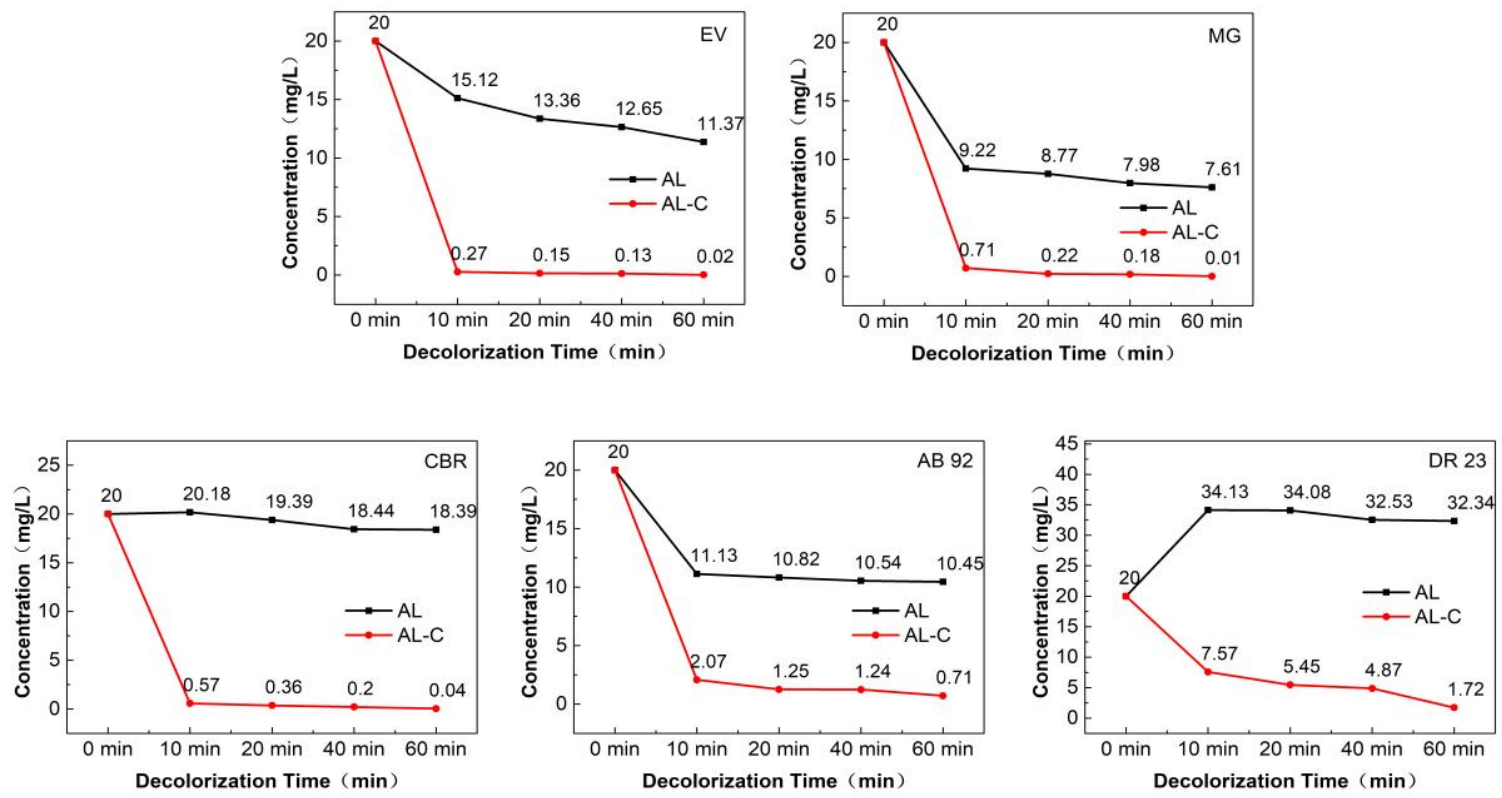

(Note: Data are average values of 5 replicates. $R S D=0.5-2.5 \%, R S D$ is relative standard deviation)

Fig. 5. Decoloration of dye wastewater by $A L$ and $A L-C$ 

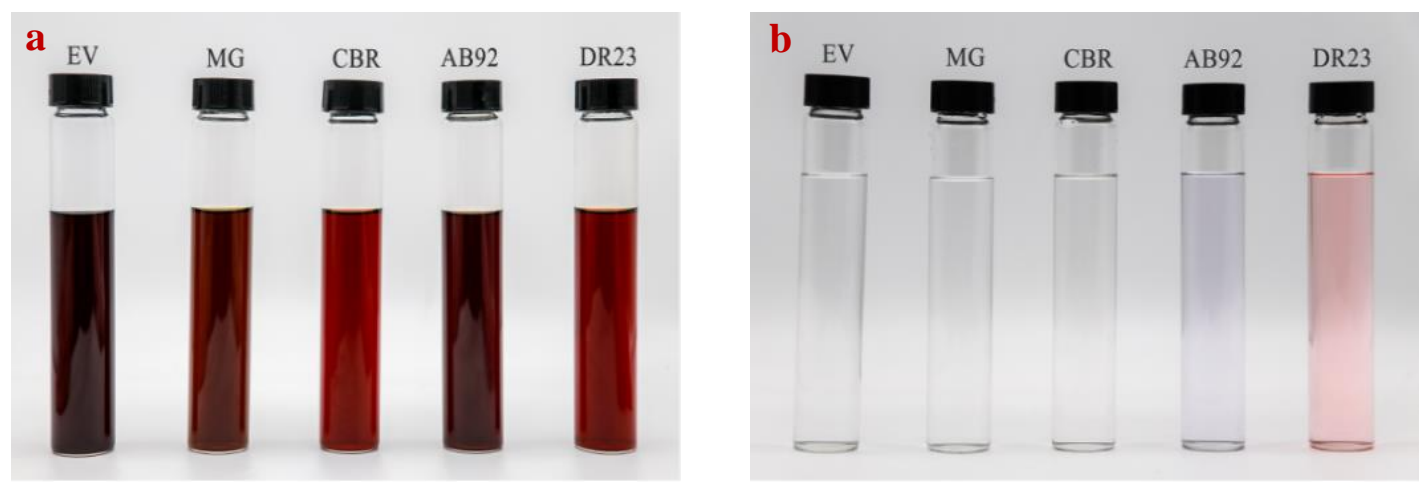

Fig. 6. Decolorization of dyes by $A L$ and $A L-C$

\section{Dye Adsorption by SLS-C}

The five kinds of simulated dye wastewaters containing EV, MG, CBR, AB 92, and DR 23 were next treated with either SLS or SLS-C, which is summarized in Fig. 7. SLS-C could adsorb the 5 dyes significantly in $20 \mathrm{~min}$. However, SLS adsorbed dye poorly and, similar to AL, even increases the chrominance of wastewater due to its water solubility. SLS-C made the concentration of EV, MG, CBR, AB 92, and DR 23 decrease from 20 $\mathrm{mg} / \mathrm{L}$ to $0.16 \mathrm{mg} / \mathrm{L}, 0.32 \mathrm{mg} / \mathrm{L}, 0.29 \mathrm{mg} / \mathrm{L}, 0.79 \mathrm{mg} / \mathrm{L}$, and $4.70 \mathrm{mg} / \mathrm{L}$ within $20 \mathrm{~min}$, and these values further decreased to $0.12 \mathrm{mg} / \mathrm{L}, 0.20 \mathrm{mg} / \mathrm{L}, 0.32 \mathrm{mg} / \mathrm{L}, 0.78 \mathrm{mg} / \mathrm{L}$, and 3.77 $\mathrm{mg} / \mathrm{L}$, respectively, after $60 \mathrm{~min}$.
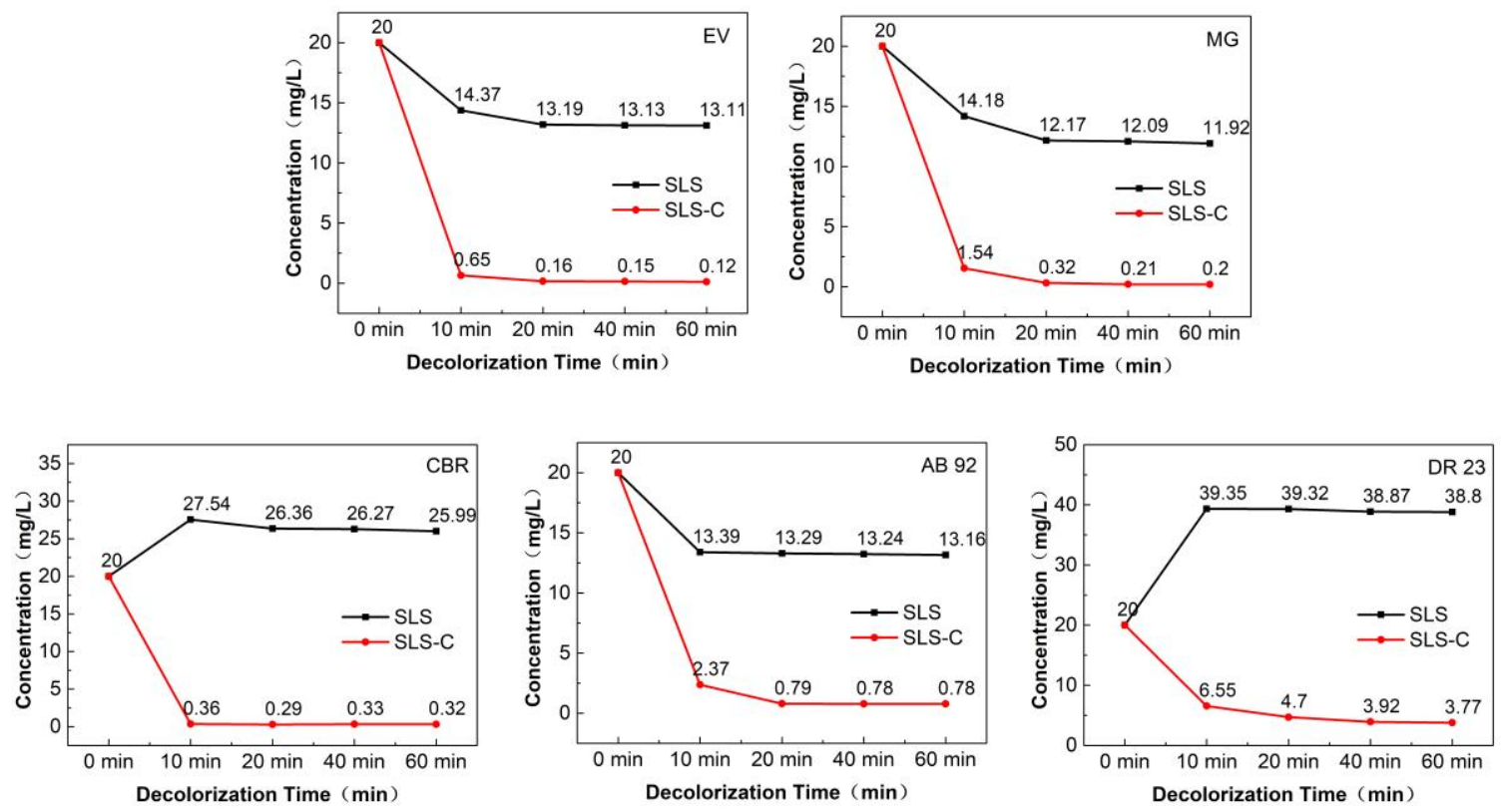

(Note: The data are average values of 5 replicates. $\mathrm{RSD}=0.5-2.5 \%, \mathrm{RSD}$ is relative standard deviation)

Fig. 7. Decoloration of dye wastewater by SLS and SLS-C 
When SLS was added to the dye containing wastewater, the concentration of EV, MG, CBR, AB 92, and DR 23, respectively, were $13.19 \mathrm{mg} / \mathrm{L}, 12.17 \mathrm{mg} / \mathrm{L}, 26.36 \mathrm{mg} / \mathrm{L}$, $13.29 \mathrm{mg} / \mathrm{L}$, and $39.32 \mathrm{mg} / \mathrm{L}$ within $20 \mathrm{~min}$. After $60 \mathrm{~min}$, the above values were transformed to $13.11 \mathrm{mg} / \mathrm{L}, 11.92 \mathrm{mg} / \mathrm{L}, 25.99 \mathrm{mg} / \mathrm{L}, 13.16 \mathrm{mg} / \mathrm{L}$, and $38.80 \mathrm{mg} / \mathrm{L}$. To summarize, the type of dye and the adsorption time also affected the decolorization by SLS-C, and SLS-C displayed better decolorization of dye wastewater than SLS.
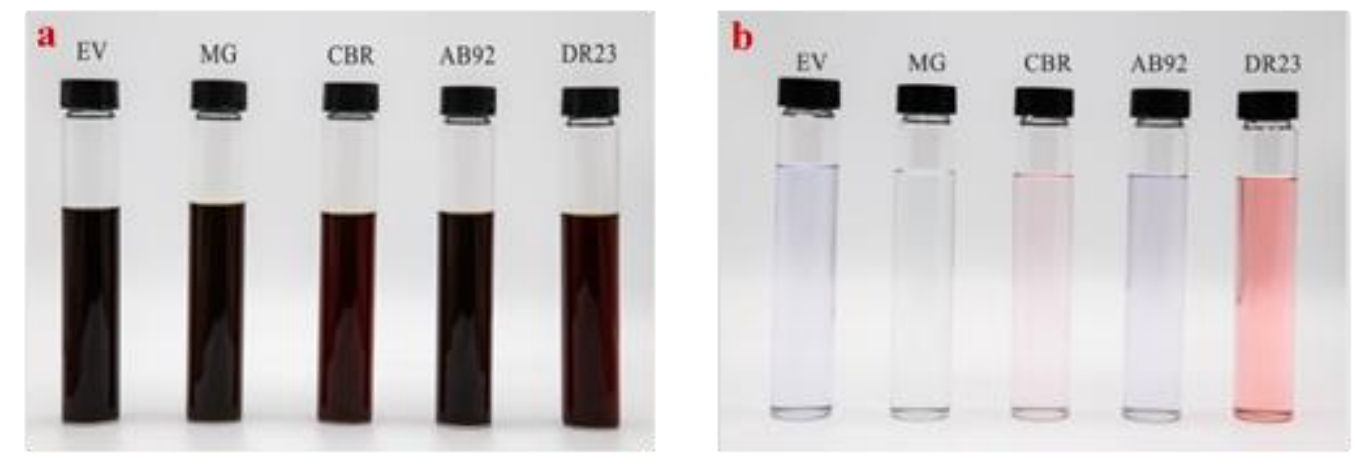

Fig. 8. Decolorization of dyes by SLS and SLS-C

The mechanisms of the obtained lignin-based carbon are mainly dependent on physical adsorption. Effective adsorption can be attributed to abundant pore structure. However, different specific surface area and ratio of micropore to mesoporous lead to different adsorption effect (Tiwari et al. 2017; Xia et al. 2017; Chen et al. 2019).

\section{CONCLUSIONS}

1. The results of this study demonstrated that low-cost activated carbons can be prepared from industrial lignin, including CLS, AL, and SLS, using one-step carbonization at $800{ }^{\circ} \mathrm{C}$ for $10 \mathrm{~h}$ without oxygen or any additional templating/activation agent.

2. SLS-C, AL-C, and CLS-C, with BET surface areas of $346 \mathrm{~m}^{2} / \mathrm{g}, 405 \mathrm{~m}^{2} / \mathrm{g}$, and 512 $\mathrm{m}^{2} / \mathrm{g}$ and total pore volumes of $0.12 \mathrm{~cm}^{3} / \mathrm{g}, 0.21 \mathrm{~cm}^{3} / \mathrm{g}$, and $0.28 \mathrm{~cm}^{3} / \mathrm{g}$, respectively, were obtained.

3. The adsorption effects of CLS-C were the best, followed by AL-C and SLS-C. However, they all had good decolorization effects on dye wastewater containing EV, MG, CBR, AB 92, and DR 23 after treatment for 10 to $20 \mathrm{~min}$.

4. These results demonstrated that activated carbons derived from industrial lignin have great potential for use in the removal of dyes from wastewater.

\section{ACKNOWLEDGMENTS}

The authors are grateful for the financial support from the Certificate of China Postdoctoral Science Foundation Grant (2019M652388), the Foundation of Guangxi Key 
Laboratory of Clean Pulp \& Papermaking and Pollution Control of China (KF201717), the National Natural Science Foundation of China (Grant No.31800499, 31600472), and the Natural Science Foundation of Shandong (ZR2018BEM026). The authors would also like to thank LetPub (PR_190730K80Y) for its linguistic assistance during the preparation of this manuscript.

\section{REFERENCES CITED}

Bulavová, P., Parmentier, J., and Slovák, V. (2018). "Facile synthesis of soft-templated carbon monoliths with hierarchical porosity for fast adsorption from liquid media," Microporous and Mesoporous Mater. 272, 155-165. DOI:

10.1016/j.micromeso.2018.06.024

Chatterjee, S., and Saito, T. (2015). "Lignin-derived advanced carbon materials," ChemSusChem. 8(23), 3941-3958. DOI: 10.1002/cssc.201500692

Chen, H., Sha, L., Zhang, Y., Liu, Y., Kong F., Zhao, X. (2019). "Facile control of corncobs-based carbons with eutectic salt $\mathrm{ZnCl}_{2} / \mathrm{NaCl}$ templated for adsorption of organic aldehyde," BioResources 14 (4), 8835-8848.

Daneshvar, N., Ayazloo, M., Khataee, A. R., Pourhassan, M. (2007). "Biological decolorization of dye solution containing malachite green by microalgae Cosmarium sp," Bioresources Technology 98 (6), 1176-1182. DOI: org/10.1016/j.biortech.2006.05.025

Fathi, M. R., Asfaram, A., and Farhangi, A. (2015). "Removal of Direct Red 23 from aqueous solution using corn stalks: Isotherms, kinetics and thermodynamic studies," Spectrochimica Acta Part A: Molecular and Biomolecular Spectroscopy 135(1), 364372. DOI: 10.1016/j.saa.2014.07.008

Fu, K., Yue, O., Gao, B., Sun, Y., and Zhu, L. (2013). "Preparation, characterization and application of lignin-based activated carbon from black liquor lignin by steam activation," Chemical Engineering Journal 1(228), 1074-1082. DOI: 10.1016/j.cej.2013.05.028

Gao, S., Chen, Y., Fan, H., Wei, X., Hu, C. L., Luo, H. and Qu, L. (2014). "Large scale production of biomass-derived $\mathrm{N}$-doped porous carbon spheres for oxygen reduction and supercapacitors," Journal of Materials Chemistry A 2(10), 3317-3324. DOI: 10.1039/C3TA14281G

Katheresan, V., Kansedo, J., and Lau, S. Y. (2018). "Efficiency of various recent wastewater dye removal methods: A review," Journal of Environmental Chemical Engineering 6(4), 4676-4697. DOI: 10.1016/j.jece.2018.06.060

Lee, J. W., Choi, S. P., Thiruvenkatachari, R., Shim, W. G., and Moon, H. (2006). "Evaluation of the performance of adsorption and coagulation processes for the maximum removal of reactive dyes," Dyes and Pigments 69(3), 196-203. DOI: 10.1016/j.dyepig.2005.03.008

Liu, X., and Antonietti, M. (2014). "Molten salt activation for synthesis of porous carbon nanostructures and carbon sheets," Carbon 1(69), 460-466. DOI: 10.1016/j.carbon.2013.12.049

Liu, Y., and Sun, D. (2007). "Effect of $\mathrm{CeO}_{2}$ doping on catalytic activity of $\mathrm{Fe}_{2} \mathrm{O}_{3} / \gamma$ $\mathrm{Al}_{2} \mathrm{O}_{3}$ catalyst for catalytic wet peroxide oxidation of azo dyes," Journal of Hazardous Materials 143(1-2), 448-454. DOI: 10.1016/j.jhazmat.2006.09.043 
Lora, J. H., and Glasser, W. G. (2002). "Recent industrial applications of lignin: A sustainable alternative to nonrenewable materials," Journal of Polymers and the Environment 10(1-2), 39-48. DOI: 10.1023/a:1021070006895

Ma, Z. S., Zhang, H. Y., Yang, Z. Z., Zhang, Y. F., and Liu, Z. M. (2014). "Highly mesoporous carbons derived from biomass feedstocks templated with eutectic salt $\mathrm{ZnCl}_{2} / \mathrm{KCl}$," J. Mater. Chem. A. 2 (45), 19324-19329. DOI: 10.1039/C4TA03829K

Mohajershojaei, K., Mahmoodi, N. M., and Khosravi, A. (2015). "Immobilization of laccase enzyme onto titania nanoparticle and decolorization of dyes from single and binary systems," Biotechnology and Bioprocess Engineering 20(1), 109-116. DOI: 10.1007/s12257-014-0196-0

Pang, J., Zhang, W., Zhang, J., Cao, G., Han, M., and Yang, Y. (2017). "Facile and sustainable synthesis of sodium lignosulfonate derived hierarchical porous carbons for supercapacitors with high volumetric energy densities," Green Chemistry 19(16), 3916-3926. DOI: 10.1039/C7GC01434A

Pang, J., Zhang, W., Zhang, H., Zhang, J., Zhang, H., Cao, G., Han, M., and Yang, Y. (2018). "Sustainable nitrogen-containing hierarchical porous carbon spheres derived from sodium lignosulfonate for high-performance supercapacitors," Carbon 1(132), 280-293. DOI: 10.1016/j.carbon.2018.02.077

Pang, J., Zhang, W., Zhang, J., Zhang, H., Cao, G., Han, M., and Yang, Y. (2018). "Oxygen and nitrogen co-enriched sustainable porous carbon hollow microspheres from sodium lignosulfonate for supercapacitors with high volumetric energy densities," ChemElectroChem 5(9), 1306-1320. DOI: 10.1002/celc.201701384

Riachy, P, Lopez, G., Emo, M., Stébé, M. J., Blin, J. L., and Ameduri, B. (2017). "Investigation of a novel fluorinated surfactant-based system for the design of spherical wormhole-like mesoporous silica," Journal of Colloid and Interface Science 1(487), 310-319. DOI: 10.1016/j.jcis.2016.10.053

Salinas-Torres, D., Ruiz-Rosas, R., Valero-Romero, M. J., Rodríguez-Mirasol, J., Cordero, T., Morallón, E., and Cazorla-Amorós. D. (2016). “Asymmetric capacitors using lignin-based hierarchical porous carbons," Journal of Power Sources 1(326), 641-651. DOI: 10.1016/j.jpowsour.2016.03.096

Tian, X., Ma, H., Li, Z., Yan, S., Ma, L., Yu, F., Wang, G., Guo, X., Ma, Y., and Wong, C. (2017). "Flute type micropores activated carbon from cotton stalk for high performance supercapacitors," Journal of Power Sources 1(359), 88-96. DOI: 10.1016/j.jpowsour.2017.05.054

Tiwari, E. M., Shukla, S. P., Dhiman, N. (2017). "Characterization and adsorption of disperse dyes from wastewater onto cenospheres activated carbon composites," Environ. Earth Sci. 76 (20) 702. DOI: 10.1007/s12665-017-7030-x

Wang, X., Jiang, C., Hou, B., Wang, Y., Hao, C., and Wu, J. (2018). "Carbon composite lignin-based adsorbents for the adsorption of dyes," Chemosphere 1(206), 587-596. DOI: 10.1016/j.chemosphere.2018.04.183

Wang, J., Zhang, G., Zhang, Z.-H., Zhang, W.-D., Zhao, G., Wen, F.-Y., Pan, Z.-J., Li, Y., Zhang, P., and Kang, P.-L. (2006). " Investigation on photocatalytic degradation of ethyl violet dyestuff using visible light in the presence of ordinary rutile $\mathrm{TiO}_{2}$ catalyst doped with upconversion luminescence agent," Water Research 40(11), 2143-2150. DOI: 10.1016/j.watres.2006.04.009

Wu, J., Ma, L., Chen, Y., Cheng, Y., Liu, Y., and Zha, X. (2016). "Catalytic ozonation of organic pollutants from bio-treated dyeing and finishing wastewater using recycled 
waste iron shavings as a catalyst: Removal and pathways," Water Research 92, 140148. DOI: 10.1016/j.watres.2016.01.053

Xia, K., Wang, G., and Zhang, H. (2017). "Synthesis of bimodal mesoporous carbon nanospheres for methyl orange adsorption," Journal of Porous Materials 24(6), 1605-1612. DOI:10.1007/s10934-017-0400-7

Zhang, G., Okajima, I., and Sako, T. (2016). "Decomposition and decoloration of dyeing wastewater by hydrothermal oxidation," The Journal of Supercritical Fluids 112, 136-142. DOI: 10.1016/j.supflu.2015.10.014

Zhao, S., Yan, T., Wang, Z., Zhang, J., Shi, L., and Zhang, D. (2017). "Removal of NaCl from saltwater solutions using micro/mesoporous carbon sheets derived from watermelon peel via deionization capacitors," RSC Advances 7(8), 4297-4305. DOI: $10.1039 / \mathrm{c} 6 \mathrm{ra} 27127 \mathrm{~h}$

Zhao, X., Li, W., Zhang, S., Liu, L., and Liu, S. (2015). "Hierarchically tunable porous carbon spheres derived from larch sawdust and application for efficiently removing $\mathrm{Cr}$ (III) and Pb (II)," Materials Chemistry and Physical 155, 52-58. DOI: 10.1016/j.matchemphys. 2015.01.064.

Article submitted: August 22, 2019; Peer review completed: October 11, 2019; Revised version received and accepted: November 5, 2019; Published: November 8, 2019.

DOI: 10.15376/biores.15.1.105-116 